\title{
Science Academies' Sixty-sixth Refresher Course in Experimental Physics
}

\author{
11-26, November 2014 \\ at Vidya Vikas Institute of Engineering and Technology, \\ \# 127-128, Lalitadripura Post, Mysore-Bannur Road, Mysore 570028 \\ Sponsored by Indian Academy of Sciences, Bangalore,
} Indian National Science Academy, New Delhi, The National Academy of Sciences, India, Allahabad

A Refresher Course in Experimental Physics will be held at Vidya Vikas Institute of Engineering and Technology, Mysore from 11 to 26 November 2014 for the benefit of faculty involved in teaching undergraduate and postgraduate courses. The Course aims to familiarize teachers with a set of new experiments developed as a low cost kit by the Indian Academy of Sciences to cater to BSc and MSc levels. All the experiments verify physical laws and principles and yield reasonably accurate results. Professor R Srinivasan, a distinguished experimental physicist, has designed these experiments for the benefit of physics teachers and students of Indian Universities. The Course comprising lectures, discussions and laboratory sessions will help participants hone their skills in experimental physics and enable them to introduce the experiments in their respective curricula.

\section{Course Director: Professor R. Srinivasan Course Coordinator: Professor C. Ningappa}

Applications are invited from teachers with experience in teaching undergraduate and postgraduate courses in Engineering and Physics. A few seats are also available for motivated students of 3rd year BSc and MSc Physics courses and PhD students with keen interest in Experimental Physics. The number of seats will be about 25. Selected participants will be provided local hospitality during the Course in addition to Course material. Outstation participants will be reimbursed three-tier $\mathrm{A} / \mathrm{c}$ train fare to Mysore and back by the shortest route. Interested applicants must submit their application ONLINE by clicking on the following link.

http://web-japps.ias.ac.in:8080/Refreshcourse/RCSS.jsp

A print copy of the application should be also sent through the Head of the Institution by speed post to: Professor C. Ningappa, Course Coordinator, Refresher Course in Experimental Physics, Department of Physics and Research Centre, Vidya Vikas Institute of Engineering and Technology, Lalitadripura Post, Mysore-Bannur Road, Mysore570028 (Phone: +91 $9844337356 /+91-0821-2471232$ (extn- 258)). In case of teacher applicants, the print copy to be forwarded by the Head of the Institution should state that leave will be sanctioned if the applicant is selected for the Course. Recommendation letter from a teacher is essential for student applicants.

For any other query, applicants can send an e-mail to: ningappacvviet@gmail.com, phyvviet@gmail.com,

\section{Last date for receipt of applications: 30 September 2014.}

Selected participants will be informed by: 10 October 2014 . 